\title{
LOW MOLECULAR WEIGHT XANTHAN PREPARED BY GAMMA IRRADIATION AND ITS EFFECTS ON DEVELOPMENT OF SEEDLINGS
}

\author{
Nguyen Van Binh, Tran Bang Diep, Hoang Dang Sang, \\ Hoang Phuong Thao, Nguyen Thi Thom, Tran Minh Quynh*
}

Hanoi Irradiation Center, Vietnam Atomic Energy Institute, Minh Khai, Tu Liem, Ha Noi, Vietnam

\begin{abstract}
Low molecular weight (Mw) xanthan was prepared by gamma Co-6o irradiation at both dry and pastelike states. The viscosity average molecular weight $(\mathrm{Mv})$ of the irradiated xanthan gradually decreased with the increase of the radiation dose. Its $\mathrm{Mv}$ slowly reduced to $1.8 \times 10^{3} \mathrm{kDa}$ from $1.1 \times 10^{4} \mathrm{kDa}$ of non-irradiated xanthan by irradiation at $500 \mathrm{kGy}$ in the solid state, and quickly reduced to $5.3 \times 10^{2} \mathrm{kDa}$ by irradiation at $50 \mathrm{kGy}$ in the pastelike state. However, the viscosity of the xanthan is still high enough for utilization as a bio-adhesive polymer. Therefore, the low Mw xanthan prepared by gamma irradiation has been studied as the additive to improve the effectiveness of fertilizer. In this study, foliar fertilizers supplemented with xanthan and irradiated xanthan were applied to maize and soybean seedlings. The results suggested that their developments were much increased by the presence of irradiated xanthan compared to initial xanthan, as indicated by the increases of their plant height, root length and fresh biomass.
\end{abstract}

Key words: Xanthan, gamma radiation, degradation, foliar fertilizer, seedling

DOI: $10.21175 /$ RadProc.2016.22

\section{INTRODUCTION}

Xanthan is usually produced by Xanthamonas campestris through bacteria fermentation. Being a natural polysaccharide with very high viscosity and molecular weight, xanthan has been widely used as food additives, especially for food preservation and processing due to its abilities to alter water flow and gel formation. Though it is not able to form a gel, the addition of xanthan gum may be applied as bioadhesive agent to reduce the amount of oil in food products, resulting in not only better microbiological stability, but also leading to healthier products [1-3]. It can also be utilized as the carrier for agrochemicals or plant protectors in order to facilitate their adhesion and remain in plant leaves [2].

In normal conditions, it hardly to be prepared as aqueous solution because of its high viscosity at even low concentration. This viscosity somewhat limited its application. However, the viscosity of xanthan may be decreased by depolymerization or decomposition like other natural polysaccharides. Some methods were applied to produce low molecular weight $(\mathrm{Mw})$ xanthan for further applications [4]. Among them, radiation degradation has been proved as one of the most effective and useful tool. Depended on radiation dose and dose rate, viscosity and $\mathrm{Mw}$ of the irradiated xanthan will reduce to some extent. Study on radiation degradation of xanthan in solid state, M. Şen et al reported that the Mw reduction was more effective by gamma irradiation at low dose rate [5].

By gamma irradiation of xanthan in solution, $\mathrm{Li}$ Yan-jie et al [6] have reported that Mw of the xanthan was reduced to half by gamma irradiation at a low dose of $5 \mathrm{kGy}$, but its $\mathrm{Mw}$ distribution become wider with the dispersity index of about 20, much influenced on its properties. They also reported that low Mw xanthan with the average molecular weight below $10 \mathrm{kDa}$ can be prepared by gamma irradiation at a dose of $120 \mathrm{kGy}$.

On the other hand, high viscosity of this low $\mathrm{Mw}$ xanthan makes it become potential bio-adhensive, which can be applied to reduce the loss of chemical fertilizers and enhance the crop yields. Though chemical fertilizers have an important role for our agriculture, they also contaminated our planet because more than 50\% NPK fertilizer did not uptake by plants. Therefore, new effective fertilizers such as organic fertilizers, foliar fertilizers... are being developed to replace chemical fertilizers [7-9].

Polysaccharides and their derivatives were studied as plant promoters, elicitors or stimulators, but their high molecular weight somewhat limited to the uptake of plants [10]. Recent years, gamma irradiation has been proved as a useful way to degrade polysaccharides to produce low $\mathrm{Mw}$ or oligo-saccharides. Radiation degradation may improve bioactivity of the irradiated products because its functional groups seemed not to be affected during radiation. In our previous study, various low $\mathrm{Mw}$ chitosan fragments have been

\footnotetext{
*tmqthuquynh@gmail.com
} 
prepared by gamma radiation for utilization as antimicrobial agents in food preservation and textile.

In this study, both xanthan in powder and solution states were gamma irradiated under Cobalt-6o source. The radiation effects on viscosity and $\mathrm{Mw}$ of xanthan were investigated with radiation dose. The xanthan solutions of various concentrations were supplemented to the foliar fertilizer, which applied to the maize and soybean for investigation of their effects on the developments of seedlings.

\section{EXPERIMENTAL}

\subsection{Materials}

Xanthan is a China product which was purchased from BaDinh technology Co. NI-PHOS-KA foliar fertilizers was kindly supported by NamBac Co. (Vietnam). All of the other chemicals were bought from Wako Pure Chemicals.

\subsection{Radiation treatment}

Xanthan was dissolved in distilled water to an aqueous solution of $\sim 2.5 \%$. Both xanthan powder and solution were irradiated under Co-6o source at Hanoi Irradiation Center with dose ranges of 10-500 kGy and 10-50 kGy for solid and liquid states, respectively.

\subsection{Measurements}

The polymer solutions were prepared in $0.1 \mathrm{M} \mathrm{KCl}$ as solvent and their relative viscosities were measured for estimate their intrinsic viscosity and viscosity average molecular weight. Relative viscosity $\left(\eta_{\mathrm{r}}\right)$ of the xanthan solutions was calculate as the ratio of flow times of a xanthan solution to pure solvent through capillary viscometer at $25^{\circ} \mathrm{C}$. Its intrinsic viscosity [ $\left.\eta\right]$ was obtained by extrapolating its reduced viscosity $\left(\eta_{\text {red }}=\left(\eta_{\mathrm{r}}-1\right) / \mathrm{c}\right)$ when the polymer concentration reduces to zero. [ $\eta$ ] value in $\mathrm{dL} / \mathrm{g}$ can be determined as the intercept of linear relationship between $\eta_{\text {red }}$ and polymer concentration (c). The viscosity average molecular weight of xanthan (Mv) was calculated with the following equation [11]:

$$
[\eta]=k_{m} \times M_{v}{ }^{a}(m L / g)
$$

where $\mathrm{k}_{\mathrm{m}}=1.7 \times 10^{6} \mathrm{dL} / \mathrm{g}, \mathrm{a}=1.14$, respectively [5]

Different xanthan samples were admixtured to the foliar fertilizers at 50 and $100 \mathrm{ppm}$ to prepare the spraying solutions, which applied to maize and soybean seedlings. After a predetermined period from spraying, the effects of xanthan on the plant growth were investigated as the changes in the plant height, root length and fresh biomass of the seedlings.

\section{RESULTS AND DISCUSSIONS}

\subsection{Change in viscosity and viscosity-average molecular weight (Mv) of irradiated xanthan}

By radiation treatment, the solubility of irradiated xanthan much increased and the time required for dissolving the irradiated xanthan gradualy reduced with increasing of radiation dose. For the xanthan irradiated in powder, its relative viscosity quickly decreased with radiation dose to $100 \mathrm{kGy}$, then slowly decreased with further increase of radiation dose, but it was high enough for the application as a bio-adhesive. The same tendency was also observed for the xanthan irradiated in solution (the data not shown).

As can be seen from Fig. 1 and Fig. 2, viscosity average molecular weight (Mv) of the initial xanthan was significantly decreased by gamma radiation. This reduction can be divided into two steps. First, initial $\mathrm{Mv}$ above $1000 \mathrm{kDa}$ quickly reduced to around 3500 $\mathrm{kDa}$ when the radiation dose increased to 100 and 10 $k G y$ for the xanthan irradiated in solid and solution, respectively. As the dose further increased, the $\mathrm{Mv}$ reductions of xanthan become slower.

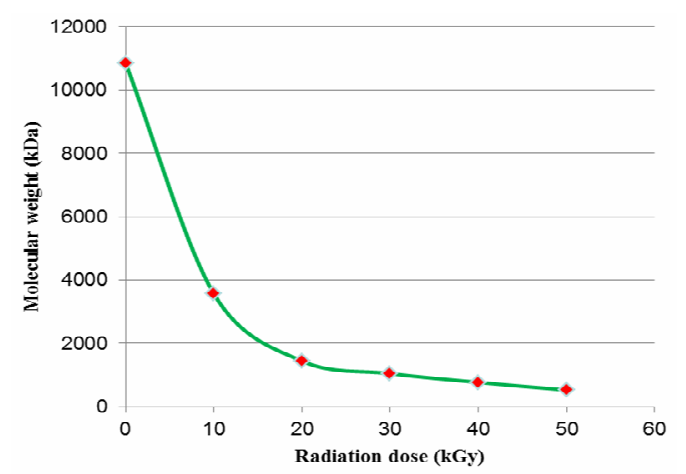

Figure 2. Viscosity average molecular weight of the xanthan irradiated in a solution as the function of radiation dose

Similar to other polysaccharides, the radiation degradation yield of xanthan, which irradiated in the solution, was higher than that in the solid state. Thus, gamma irradiation can be applied as effective way for prepareation of low Mv xanthan.

\subsection{Effects of xanthan and irradiated xanthan on the growth of seedlings}

Table 1. The effects of the foliar fertilizers containing xanthan on the growth of maize seedlings

\begin{tabular}{|l|c|c|c|}
\hline Sample & $\begin{array}{c}\text { Plant height } \\
(\mathrm{cm})\end{array}$ & $\begin{array}{c}\text { Root length } \\
(\mathrm{cm})\end{array}$ & $\begin{array}{c}\text { Fresh } \\
\text { biomass }(\mathrm{g})\end{array}$ \\
\hline Control & $38.3 \pm 0.21$ & $7.6 \pm 0.32$ & $76.4 \pm 0.36$ \\
\hline XT0-50 & $39.7 \pm 0.38$ & $8.1 \pm 0.33$ & $85.3 \pm 0.27$ \\
\hline XTo-100 & $40.3 \pm 0.22$ & $8.2 \pm 0.25$ & $86.2 \pm 0.23$ \\
\hline XT50-50 & $44.6 \pm 0.28$ & $8.7 \pm 0.36$ & $100.6 \pm 0.34$ \\
\hline XT50-100 & $44.1 \pm 0.23$ & $8.6 \pm 0.34$ & $99.4 \pm 0.48$ \\
\hline XT100-50 & $44.2 \pm 0.29$ & $8.7 \pm 0.28$ & $99.5 \pm 0.24$ \\
\hline XT100-100 & $44.9 \pm 0.24$ & $8.7 \pm 0.37$ & $100.4 \pm 0.31$ \\
\hline
\end{tabular}




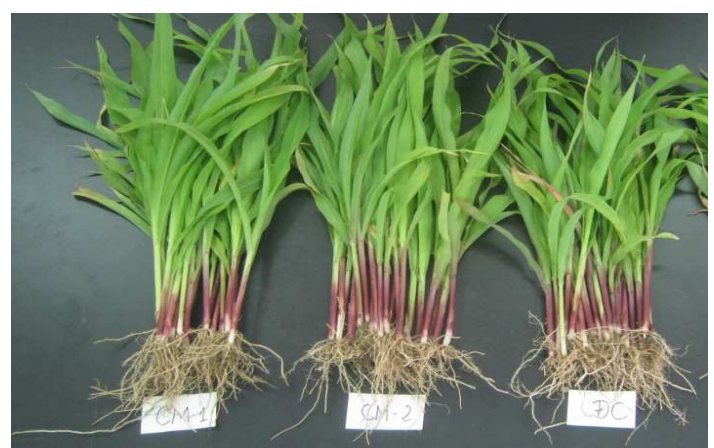

Figure 3. Effects of foliar fertilizer supplemented with $50 \mathrm{ppm}$ of xanthan irradiated at $50 \mathrm{kGy}(\mathrm{CM}-1), 100 \mathrm{kGy}(\mathrm{CM}-2)$, and without xanthan as control (DC) on the growth of maize

Study on the adhesion properties of xanthan and its effects on the development of plant, the xanthan samples that irradiated at 0,50 and $100 \mathrm{kGy}$ (XTo, XT5O and XT 100) were added to Niphoska foliar fertilizer into the solution with xanthan concentration of 50 and $100 \mathrm{ppm}$. After fertilization and development during 4 weeks, the seedlings were collected and their plant height, length root and fresh biomass were calculated and presented in Table 1 and 2. The changes in plant morphology also observed in Fig 3 and 4.

Table 2. The effects of the foliar fertilizers containing xanthan on the growth of soybean seedlings

\begin{tabular}{|l|c|c|c|}
\hline Sample & $\begin{array}{c}\text { Plant height } \\
(\mathrm{cm})\end{array}$ & $\begin{array}{c}\text { Root length } \\
(\mathrm{cm})\end{array}$ & $\begin{array}{c}\text { Fresh } \\
\text { biomass }(\mathrm{g})\end{array}$ \\
\hline Control & $18.4 \pm 0.56$ & $4.8 \pm 0.31$ & $30.2 \pm$ \\
\hline XTo-50 & $19.3 \pm 0.48$ & $5.1 \pm 0.29$ & $33.9 \pm 0.37$ \\
\hline XTo-100 & $19.6 \pm 0.38$ & $5.1 \pm 0.25$ & $34.2 \pm 0.52$ \\
\hline XT50-50 & $21.3 \pm 0.49$ & $5.4 \pm 0.33$ & $36.9 \pm 0.43$ \\
\hline XT50-100 & $21.8 \pm 0.54$ & $5.3 \pm 0.35$ & $37.4 \pm 0.36$ \\
\hline XT100-50 & $21.1 \pm 0.35$ & $5.3 \pm 0.39$ & $36.5 \pm 0.48$ \\
\hline XT100-100 & $21.6 \pm 0.43$ & $5.4 \pm 0.37$ & $36.6 \pm 0.38$ \\
\hline
\end{tabular}

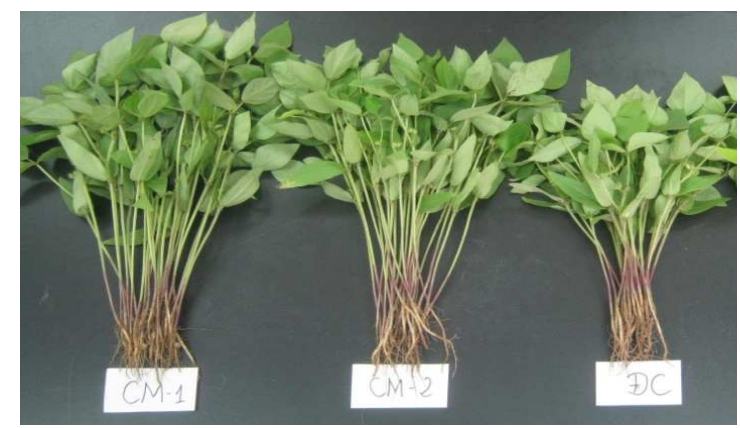

Figure 4 Effects of foliar fertilizer supplemented with $50 \mathrm{ppm}$ of xanthan irradiated at $50 \mathrm{kGy}(\mathrm{CM}-1), 100 \mathrm{kGy}(\mathrm{CM}-2)$, and without xanthan as control (DC) on the growth of soybean

It is obvious that xanthan has significantly improved the growth of plants, and the growth rate of the seedlings sprayed with the irradiated xanthan higher than that with initial xanthan. Fresh biomass of maize and soybean fertilized with the irradiated xanthan were about 30 and $20 \%$ higher than that cultivated with foliar fertilizer only, whereas their plant height and root length also increased more than $10 \%$.
However, there were no significant differences between the plants that were sprayed with foliar fertilizers containing the xanthan irradiated at 50 and $100 \mathrm{kGy}$. Therefore, the irradiated xanthan can be applied as good bio-adhensive for the foliar fertilizer.

\section{CONCLUSION}

The relative viscosity of xanthan was quickly reduced by gamma irradiation in both the dried state and the solution, whereas the decomposition of xanthan by gamma irradiation in the solution was much faster than in the solid state. Low Mv xanthan products are produced by radiation degradation at a rather small radiation dose from solution.

The effects of xanthan and the irradiated xanthan on the plant's growth were determined with maize and soybean seedlings that cultivated with Niphoska foliar fertilizers containing xanthan at concentration of 50 and $100 \mathrm{ppm}$. The results revealed that plant height, root length and fresh biomass of maize and soybean seedlings fertilized with xanthan and irradiated xanthan have significantly increased. In fact, the growth of the plant, which fertilized with the irradiated xanthan, seems not to be depended on the radiation dose. It may due to the irradiated xanthan acted as bioadhesive for the foliar fertilizer only, but not affected on the plant growth like other low Mw polysaccharides that can act as plant promotor.

Acknowledgement: This report is part of the research done within the project of CS/15/O8-O1, granted by Vietnam Atomic Energy Institute. The authors would like to thank to Hanoi Irradiation Center for other supports.

\section{REFERENCES}

1. E.D. Vega, E. Vasquez, J.R.A. Diaz and M.A. Mausuelli, "Influence of the Ionic Strength in the Intrinsic Viscosity of Xanthan Gum: an experimental review," J. Polym. Biopolym. Phys. Chem., vol. 3, no. 1, pp. 12-18, 2015

2. A. Lackke, "Xanthan - A Versatile Gum," Resonance, pp. 25-33, Oct. 2004.

3. A.M. Melaj and M.E. Daraio, "Preparation and Characterization of Potassium Nitrate ControlledRelease Fertilizers Based on Chitosan and Xanthan Layered Tablets," J. Appl. Polym. Sci., vol. 130, no. 4, pp. 2422-2428, Nov. 2013

4. H. Liu, C. Huang, W. Dong, Y. Du, X. Bai and X. Li, "Biodegradation of Xanthan by Newly Isolated Cellulomonas sp. LX, Releasing Elicitor Active XanthoOligosaccharides-Induced Phytoalexin Synthesis in Soybean Cotyledons," Proc. Biochem., vol. 40, no. 12, pp. 3701-3706, Dec. 2005

5. M. Sen et al., "Radiation Induced Degradation of Xanthan Gum in the Solid State," Rad. Phys. Chem., vol. 124, pp. 225-229, July 2016

6. L. Yanjie, H. Yiming, W. Feng and L. Yongfu, "Effect of Irradiation on Molecular Weight and Antioxidant Activity of Xanthan Gum," J. Nucl. Agricul. Sci.; vol. 24, no. 6, pp. 1208-1213, 2010

7. V. Orbovic, J.L. Jifon and J.P. Syvertsen, "Foliar-Applied Surfactants and Urea Temporarily Reduce Carbon Assimilation of Grapefruit Leaves," J. Amer. Soc. Hort. Sci., vol. 126, no. 4, pp. 486-490, July 2001

8. D. Stock and P.J. Holloway, "Possible Mechanisms for Surfactant-Induced Foliar Uptake of Agrochemicals," Pest. Sci., vol. 38, no. 2-3, pp. 165-177, 1993 
9. P. Wojcik, "Uptake of Mineral Nutrients from Foliar Fertilization (Review)," J. Fruit Ornam. Plant Res., vol. 12, pp. 201-218. 2004

10. X. Zhang and J. Liu, "Effect of Arabic Gum and Xanthan Gum on the Stability of Pesticide in Water Emulsion," $J$. Agric. Food Chem., vol. 59, no. 4, pp. 1308-1315, 2011

11. M. Milas, M. Rinaudo and B. Tinland, "The Viscosity Dependence on Concentration, Molecular Weight and Shear Rate of Xanthan Solutions," Polym. Bull., vol. 14, no. 2, pp. 157-164, Aug. 1985

12. A. Alexander and M. Schroeder, "Fertilizer Use Efficiency: Modern Trends in Foliar Fertilization," $J$. Plant Nutrit., vol. 10, no. 9-16, pp. 1391-1399, 1987 